\title{
Role of mode of heating on the synthesis of nanocrystalline zinc ferrite
}

\author{
Prashant R. Chaudhari • V. M. Gaikwad • \\ S. A. Acharya
}

Received: 11 May 2013/Accepted: 27 September 2014/Published online: 12 October 2014

(C) The Author(s) 2014. This article is published with open access at Springerlink.com

\begin{abstract}
In the present work, microwave-assisted coprecipitation route was used for synthesis of nanocrystalline zinc ferrite and results were compared with conventionally prepared zinc ferrite. Synthesis conditions were kept uniform in both cases, except that the mode of heating was changed. The effects of mode of heating on the material properties were studied systematically. Microstructures of both samples were studied by scanning electron microscopy and transmission electron microscopy and the particle size was found to be in the range of 3-4 $\mathrm{nm}$. Particle size distribution in microwaveprocessed $\mathrm{MS}-\mathrm{ZnFe}_{2} \mathrm{O}_{4}$ is found to be highly uniform compared to conventionally processed samples $\left(\mathrm{CS}-\mathrm{ZnFe}_{2} \mathrm{O}_{4}\right)$. XRD data confirmed the presence of single-phase face-centered cubic structure for both the samples. The XRD data fitted well with Reitveld refinement. The functional groups were analyzed by FT-IR. Local distortions in the structures were studied by FT-Raman spectra of zinc ferrites at room temperature. This study concludes that the microwaveassisted synthesis route reduced the time of reaction by around $23 \mathrm{~h}$ and developed uniformly distributed fine-scaled particles. This method has high potential to synthesize other ferrite materials also.
\end{abstract}

Keywords Nanocrystalline zinc ferrite Coprecipitation route $\cdot$ Microwave- and conventional-processing techniques - Raman spectra

P. R. Chaudhari

Department of Physics, DMIETR, Sawangi (Meghe), Wardha, MS, India

V. M. Gaikwad · S. A. Acharya (ه)

Department of Physics, RTM Nagpur University, Nagpur, MS, India

e-mail:saha275@yahoo.com

\section{Introduction}

Ferrites having spinel crystal structure are widely used in a number of electronic devices because of their high permeability at high frequency, remarkably high electrical resistivity, mechanical hardness, chemical stability, and reasonable cost. Spinels of the type $\mathrm{A}^{2+} \mathrm{B}_{2}^{3+} \mathrm{O}_{4}$ are intensively focused due to their wide applications in several technological fields (Bettinger et al. 2007), where A and B refer to the tetrahedral and octahedral sites, respectively, in the oxygen lattice. There are different technological applications such as high-density magnetic recording, biomedicine, targeted drug delivery, magnetic fluids, data storage, spintronics, solar cells, sensors, and catalysis (Yin and Alivisatos 2005; El-Sayed 2004; Geng et al. 2007; Lu et al. 2007). $\mathrm{ZnFe}_{2} \mathrm{O}_{4}$ is one of the most important spinel ferrites which exhibits properties for application as soft magnets and low loss materials at high frequencies (Son et al. 2002). Zinc ferrite $\left(\mathrm{ZnFe}_{2} \mathrm{O}_{4}\right)$ is of interest not only to basic research in magnetism, but also has great potential in technological applications, such as magnetic materials (Ehrhardt et al. 2003; Bid and Pradhan 2003; Kundu et al. 2003; Tanaka et al. 1998; Grasset et al. 2002; Deng et al. 2005; Sousa et al. 2001), gas sensors (Niu et al. 2004), catalysts (Toledo-Antonio et al. 2002), photocatalysts (Qiu et al. 2004), and absorbent materials (Kobayashi et al. 2002, 2002; Pineda et al. 1997; Ikenaga et al. 2004; ToḿasAlonso and Latasa 2004), and is described by the formula (A) $(B)_{2} \mathrm{O}_{4}$. Spinel ferrites possess a cubic structure, where (A) and (B) indicate tetrahedral and octahedral cation sites in a face-centered cubic anion (oxygen) sublattice, respectively. Bulk $\mathrm{ZnFe}_{2} \mathrm{O}_{4}$ has a normal spinel structure with $\mathrm{Zn}^{2+}$ ions in the A-site and $\mathrm{Fe}^{3+}$ ions in the B-sites. However, in contrast to the bulk compound, the 
nanocrystalline $\mathrm{ZnFe}_{2} \mathrm{O}_{4}$ system always shows up as a mixed spinel in which $\mathrm{Zn}^{2+}$ and $\mathrm{Fe}^{3+}$ ions are distributed over the A- and B-sites. This cationic rearrangement leads to the formation of two magnetic sublattices, which are responsible for the enhanced magnetization when compared with normal $\mathrm{ZnFe}_{2} \mathrm{O}_{4}$ (Sepelak et al. 1997; Oliver et al. 2000; Jeyadevan et al. 1994).

The physical properties of ferrites are dependent on several factors such as the preparation method, sintering process, and the type and amount of constituent elements or additives (Yadoji et al. 2003). There are two main factors which cause nanomaterials to behave significantly differently from bulk materials: (I) surface effects (causing a smooth scaling of properties due to the fraction of atoms on the surface) and (II) quantum effects (showing discontinuous behavior due to quantum confinement effects in materials with delocalized electrons) (Roduner 2006). These factors affect the chemical reactivity of materials and physical properties such as mechanical, optical, electrical, and magnetic properties.

Cubic spinel ferrites system shows significant changes in its magnetic properties by reducing the grain size at nanoscale. Tang et al. have finely tuned particle size by controlling the annealing temperature, and the effect of particle size on magnetic behavior has been reported (Tung et al. 2002). The blocking temperature has been found to increase and the (effective) anisotropy constant $\mathrm{K}_{\mathrm{A}}$ decreases with increasing particle size. The latter effect is attributed to the smaller contribution of the surface anisotropy when the particle size increases. Bulk zinc ferrite has a completely normal spinel structure with $\mathrm{Zn}$ ions in the tetrahedral or $\mathrm{A}$ sites and Fe ions in the octahedral or B sites (Changwa et al. 2007). In contrast to the bulk compound, the nanocrystalline $\mathrm{ZnFe}_{2} \mathrm{O}_{4}$ system always shows up as a mixed spinel, which may rearrange $\mathrm{Zn}$ and $\mathrm{Fe}$ at $\mathrm{A}$ and $\mathrm{B}$. It leads to change in the physical behavior. The mode and conditions of synthesis play very important role in particle size manipulation. Various synthesis methods, such as dry and wet milling (Ozcan et al. 2005), sol-gel, coprecipitation (Atif et al. 2006; Kumar 1999), microemulsion (Wakiya et al. 2007), pulsed laser deposition, electrode position ( $\mathrm{Li}$ et al. 2006), thermal solid-state reaction (Sivakumar et al. 2006), an ultrasonic cavitation approach (Changwa et al. 2007), thermal decomposition of metal-surfactant complexes (Huayun et al. 2012), hydrothermal and solvothermal methods (Gul et al. 2013), have been reported for the preparation of nanometer $\mathrm{ZnFe}_{2} \mathrm{O}_{4}$ particles.

In the present study, we have prepared $\mathrm{ZnFe}_{2} \mathrm{O}_{4}$ nanoparticles by the coprecipitation technique. The effects of the mode of heating during synthesis on structure, size, and morphology of the $\mathrm{ZnFe}_{2} \mathrm{O}_{4}$ nanoparticles were systematically investigated. XRD, SEM, and TEM techniques were used to study the structure and morphology of the samples. Functional groups were analyzed by FT-IR. The effect of the synthesis parameters on local distortion in structure were studied by FT-Raman spectra of $\mathrm{ZnFe}_{2} \mathrm{O}_{4}$ at room temperature.

\section{Experimental}

For the synthesis of nanoparticles of Zinc ferrites, the homogeneous coprecipitation route was used. All precursor $\mathrm{Zn}\left(\mathrm{NO}_{3}\right)_{3} \cdot 6 \mathrm{H}_{2} \mathrm{O}(\mathrm{AR})$ and $\mathrm{Fe}\left(\mathrm{NO}_{3}\right)_{3} \cdot 9 \mathrm{H}_{2} \mathrm{O}$ were procured from Sigma-Aldrich with $99.9 \%$ purity. For preparation, $\mathrm{Zn}\left(\mathrm{NO}_{3}\right)_{3} \cdot 6 \mathrm{H}_{2} \mathrm{O}$ and $\mathrm{Fe}\left(\mathrm{NO}_{3}\right)_{3} \cdot 9 \mathrm{H}_{2} \mathrm{O}$ were dissolved in deionized water with stoichiometry of $\left[\mathrm{Zn}^{2+}\right]=0.10 \mathrm{~mol} / \mathrm{L}$ and $\left[\mathrm{Fe}^{3+}\right]=0.20 \mathrm{~mol} / \mathrm{L}$ in the mixed solution. A solution of $6.0 \mathrm{~mol} / \mathrm{L} \mathrm{NaOH}$ was added drop-wise under stirring into a $50.0 \mathrm{~mL}$ mixed solution to adjust the $\mathrm{pH}$ of the admixture to 12 (optimized value). The admixture was transferred into a round bottom flask with reflux arrangement and placed on a hot plate with continuous stirring. The hot plate was kept at different temperatures starting from 120 to $200{ }^{\circ} \mathrm{C}$ and processed at different time and then allowed to cool to room temperature naturally. The best results were obtained for samples processed at $140{ }^{\circ} \mathrm{C}$ for $24 \mathrm{~h}$. To process the reaction in a microwave, the admixture was transferred into a round bottom flask and sealed and heated in a microwave-refluxing system with a magnetic stirrer at different power levels and different processing times. The microwave-refluxing system used for the processing is of $360 \times 210 \times 430 \mathrm{~mm}$-dimension chamber with a $2.45 \mathrm{GHz}$ frequency multimode source. The maximum deliverable power output was $700 \mathrm{~W}$. We prepared the samples at different conditions of microwave power and irradiation time. The best results were obtained for sample processed at $700 \mathrm{~W}$ for $45 \mathrm{~min}$ of processing time. The corresponding temperature was measured as $120{ }^{\circ} \mathrm{C}$. The solute was separated from the solvent by centrifugation and washed with water and ethanol five times, followed by drying at $70{ }^{\circ} \mathrm{C}$ overnight to obtain a precursor. The as-synthesized sample was used for structural characterization.

At room temperature, powder XRD was carried out on the as-synthesized and calcined $\mathrm{CS}-\mathrm{ZnFe}_{2} \mathrm{O}_{4}$ and MS$\mathrm{ZnFe}_{2} \mathrm{O}_{4}$ samples for phase identification and for the crystallite size estimation, using a Bruker D8 Advance $\mathrm{X}$-ray diffractometer with $\mathrm{CuK} \alpha$ radiation at a scanning rate of $1 \mathrm{~min}^{-1}$. The XRD patterns were collected in the $2 \theta$ range of $10^{\circ}-70^{\circ}$ at room temperature with an angle step size of $0.013^{\circ}(2 \theta)$ and $8 \mathrm{~s}$ counting time to ensure sufficient resolution for structural refinements by the Rietveld method using Fullprof software. The morphology of the samples was observed using a scanning 
electron microscope (SEM, JEOL-6360) and transmission electron microscope (TEM, Technai $20 \mathrm{G}^{2}$ ) operated at an accelerating voltage of $200 \mathrm{keV}$ using carbon-coated formvar grids. The sample was prepared by dispersing the nanostructures in N,N-dimethylformamide (DMF) using ultrasonication. The formation of metal-O bonds in the $\mathrm{CS}$ and $\mathrm{MS}-\mathrm{ZnFe}_{2} \mathrm{O}_{4}$ powder sample was confirmed by FT-IR System, Perkin Elmer Spectrum One, Instrument. FT-RAMAN spectra of the powders were recorded by BRUKER RFS 27: Stand-alone FT-Raman Spectrometer.

\section{Results and discussion}

The powder X-ray diffraction patterns of CS and MS-zinc ferrites powder calcined at different temperatures are shown in Figs. 1 and 2, respectively. It can be clearly seen from the XRD data that as-synthesized powder is in amorphous form for both the samples. However, after calcination at $400{ }^{\circ} \mathrm{C}$, crystalline nature was observed to develop in both the samples with crystal growth along the direction (220), (311), (422), and (440). By raising the temperature of calcination from 400 to $600{ }^{\circ} \mathrm{C}$, the degree of crystallinity is found to increase with the introduction of a new plane (422). After $800{ }^{\circ} \mathrm{C}$ calcination, highly crystalline natures are exhibited by both XRD patterns (Figs. 1 and 2, respectively). Both XRD data are well matched with single-crystalline cubic spinel form of zinc ferrite with JCPDS Card No. 82-1049 having lattice constant $a=8.44 \AA$ with space group Fd3 m (227). Absence of any peak from $\mathrm{ZnO}, \mathrm{Fe}_{2} \mathrm{O}_{3}$ or any other oxide phases confirmed the formation of phase-pure zinc ferrite.

The mean particle diameter was calculated from the XRD pattern according to the line width of the $\left(\begin{array}{lll}3 & 1 & 1\end{array}\right)$ plane refraction peak using the following Debye-Scherrer equation $D=\frac{K \lambda}{\beta \cos \theta}$. The equation uses the reference peak width at angle $\theta$, where $\lambda$ is the X-ray wavelength $(1.5418 \AA), \beta$ is the width of the XRD peak at half-height, and $K$ is the shape factor, about 0.9 for spherical-shaped particles. The average crystallite size calculated from the peak width is about $4-5 \mathrm{~nm}$ in both the samples. Structural refinement of microwave and conventional ZFO was carried out by the Rietveld method using Fullprof program, assuming Fd3 m cubic space group. Structural Rietveld refinements yielded satisfactory fits. Generally, it is implemented to refine all structural parameters (lattice cell constants, atomic positions, and occupancies). The background was modeled with a polynomial and the profile was fitted with a pseudo-Voigt analytical function. For both the $\mathrm{K} \alpha_{1}$ and $\mathrm{K} \alpha_{2}$ profiles, the line-broadening function $\mathrm{B}(2 \theta)$ and the symmetric part of instrumental function $S(2 \theta)$ are

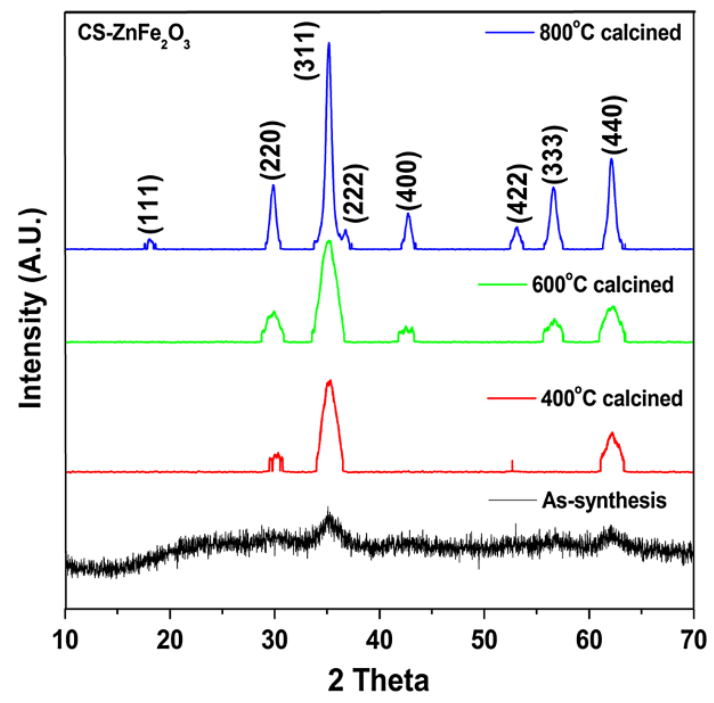

Fig. 1 XRD pattern of $\mathrm{CS}-\mathrm{ZnFe}_{2} \mathrm{O}_{4}$ powder calcined at different temperatures

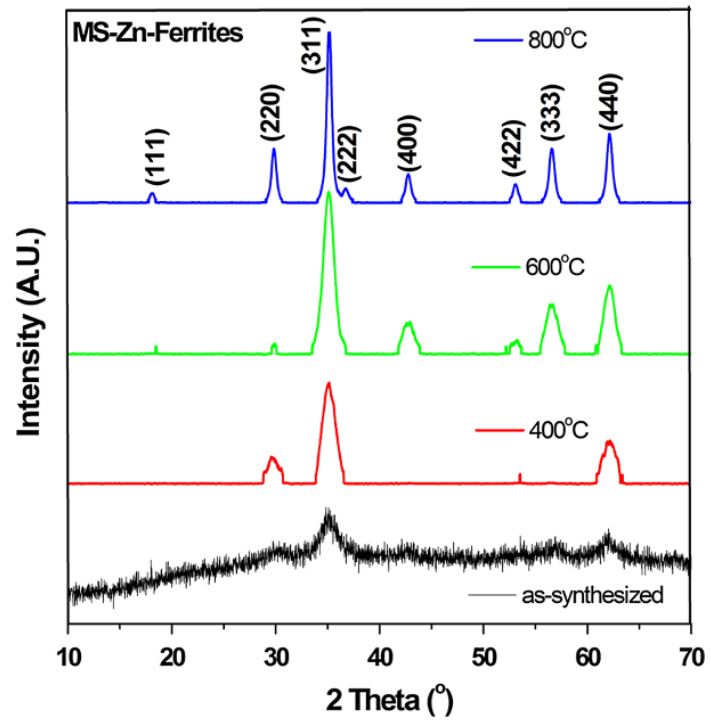

Fig. 2 XRD pattern of $\mathrm{MS}-\mathrm{ZnFe}_{2} \mathrm{O}_{4}$ powder calcined at different temperatures

represented by the pseudo-Voigt function. The pseudoVoigt function is given by;

$\mathrm{pV}(x)=\Sigma I_{\mathrm{nt}}[\eta C(x)+(1-\eta) G(x)]$

where $C(x)=\left(1+x^{2}\right)-1$ is the Cauchyian component and $C(x)=\exp \left[-(\ln 2) x^{2}\right]$ is the Gaussian component. Considering the integrated intensity of the peaks as a function of structural parameters only, the Marquardt leastsquares procedures were adopted for minimization of the difference between the observed and calculated powder diffraction patterns. The minimization was carried out using the reliability index parameter such as the residuals for the weighted pattern $\left(R_{\mathrm{wp}}\right)$, the pattern $\left(R_{\mathrm{p}}\right)$, Braggs 


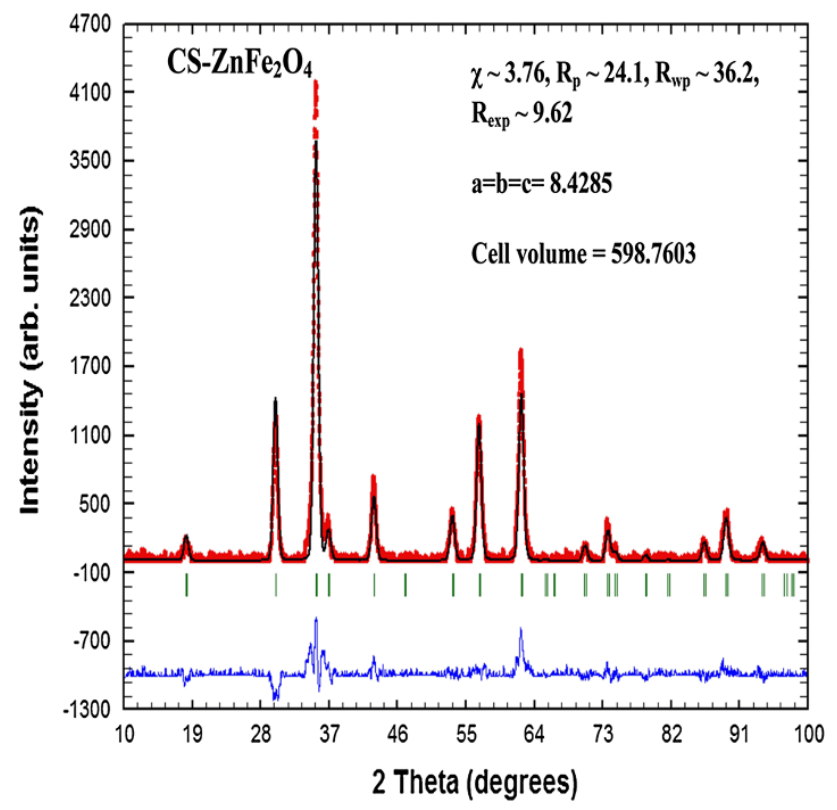

Fig. 3 Rietveld refinement fitting of $\mathrm{CS}-\mathrm{ZnFe}_{2} \mathrm{O}_{4}$

factor $\left(R_{\mathrm{Bragg}}\right)$, structure factor $\left(R_{\mathrm{F}}\right)$, and goodness of fit $\left(\chi^{2}\right)$. All these parameters are used as numerical criteria of the quality of fit of calculated to experimental diffraction data and represented by following relations (Kumar and Varshney 2012; Wang et al. 2002):

$R_{\mathrm{wp}}=\left[\frac{\sum_{i=1, n} w_{i}\left(y_{i(\mathrm{obs})}-y_{i(\mathrm{cal})}\right)^{2}}{\sum_{i=1, n} w_{i}\left(y_{i(\mathrm{obs})}\right)^{2}}\right]^{\frac{1}{2}} \times 100$

$R_{\mathrm{p}}=\frac{\sum_{i=1, n}\left|y_{i(\mathrm{obs})}-y_{i(\mathrm{cal})}\right|}{\sum_{i=1, n} y_{i(\mathrm{obs})}} \times 100$

$R_{\text {Bragg }}=\frac{\sum\left|I_{(\mathrm{obs})}-I_{(\mathrm{cal})}\right|}{\sum\left|I_{(\mathrm{obs})}\right|} \times 100$

$R_{\exp }=\left[\frac{n-p}{\sum_{i=1, n} w_{i}\left(y_{i(\mathrm{obs})}\right)^{2}}\right]^{1 / 2}$

$R_{\mathrm{wp}}=\sum_{i=1, n} \frac{w_{i}\left(y_{i(\mathrm{obs})}-y_{i(\mathrm{cal})}\right)^{2}}{n-p+c} \times 100$,

where $y_{i(\mathrm{obs})}$ is the experimental intensities, $y_{i(\mathrm{cal})}$ is the calculated intensities, $w_{i}=\left(1 / y_{i(\mathrm{obs})}\right)$ is the weight experimental observations, $n$ is the number of experimental observations, $p$ is the number of fitting parameters and $I$ is the integrated intensity. The goodness of fit (GOF) is established by comparing $R_{\mathrm{wp}}$ with the expected error, $R_{\text {exp }}$,

$\chi^{2}(\mathrm{GOF})=\frac{R_{\mathrm{Wp}}}{R_{\exp }}$.

Refinement is carried out until fit converged and GOF factor becomes close to 1 . ZFO was found to be a well-

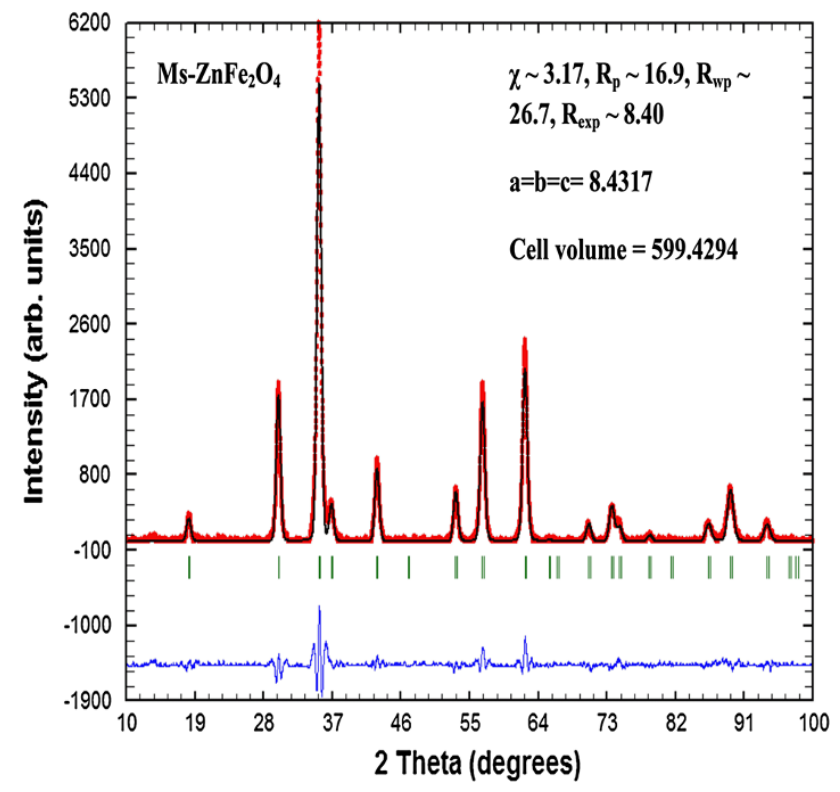

Fig. 4 Rietveld refinement fitting of $\mathrm{MS}-\mathrm{ZnFe}_{2} \mathrm{O}_{4}$

crystallized single phase, presenting a cubic spinel structure (space group $\mathrm{Fd} 3 \mathrm{~m}$ ). Figures 3 and 4 show the Rietveld refinement of the ZFO, with the experimental curve, Rietveld calculated lines (Bragg's position), and the difference curves. From the absence of additional reflections, it is clear that the samples are in single phase. Structural data obtained from XRD and Rietveld fitting are compared with JCPDS and summarized in Table 1.

The SEM images of CS and $\mathrm{MS}-\mathrm{ZnFe}_{2} \mathrm{O}_{4}$ samples are shown in Figs. 5 and 6, respectively. Both images reveal very fine size of particles below $100 \mathrm{~nm}$. Figure 5 exhibits highly agglomerated and non-uniform roughly spherical particles of $\mathrm{CS}-\mathrm{ZnFe}_{2} \mathrm{O}_{4}$. The microstructure of MS$\mathrm{ZnFe}_{2} \mathrm{O}_{4}$ (Fig. 6) reveals less agglomerated, uniformly distributed particles. Agglomeration makes determining the exact size and shape of the particles difficult. Hence, TEM was employed to visualize the size and shape and to confirm the nanocrystalline nature of the as-synthesized zinc ferrite. Figures 7 and 8 show the typical bright field TEM image of the as-synthesized CS and $\mathrm{MS}-\mathrm{ZnFe}_{2} \mathrm{O}_{4}$ nanoparticles, respectively. The TEM image is clear evidence for dense assembly of uniformly sized ferrite nanoparticles for $\mathrm{MS}-\mathrm{ZnFe}_{2} \mathrm{O}_{4}$, but heavy agglomeration and non-uniformity for $\mathrm{CS}-\mathrm{ZnFe}_{2} \mathrm{O}_{4}$. The whole surface of the grid was covered with ferrite nanoparticles as shown in this image. It can be seen from the TEM image that the distribution of zinc ferrite nanoparticles are polydispersed and are essentially spherical. Average particle size determined from TEM image is in the range of 4-5 $\mathrm{nm}$ approximately for both the samples, which is also in accordance with the result calculated by the Scherrer formula. Comparative 
Table 1 Comparative lattice parameters from XRD, JCPDS, and Rietveld, and particle size by the Scherrer formula and TEM

\begin{tabular}{lllllll}
\hline $\begin{array}{l}\text { Synthesis } \\
\text { method/mode } \\
\text { of heating }\end{array}$ & $\begin{array}{l}\text { Calcination } \\
\text { temperature } \\
\text { (deg celsius) }\end{array}$ & $\begin{array}{l}\text { Lattice parameter } \\
\text { JCPDS A }\end{array}$ & $\begin{array}{l}\text { Lattice parameter } \\
\text { calculated A }\end{array}$ & $\begin{array}{l}\text { Lattice parameter } \\
\text { from Rietveld } \\
\text { refinement A }\end{array}$ & $\begin{array}{l}\text { Particle size } \\
\text { from Scherrer } \\
\text { formula (nm) }\end{array}$ & $\begin{array}{l}\text { Partial size } \\
\text { from TFM } \\
(\mathrm{nm})\end{array}$ \\
\hline $\begin{array}{l}\text { Microwave } \\
\text { Conventions }\end{array}$ & 400 & 8.440 & 8.4394 & & 4 \\
\hline
\end{tabular}

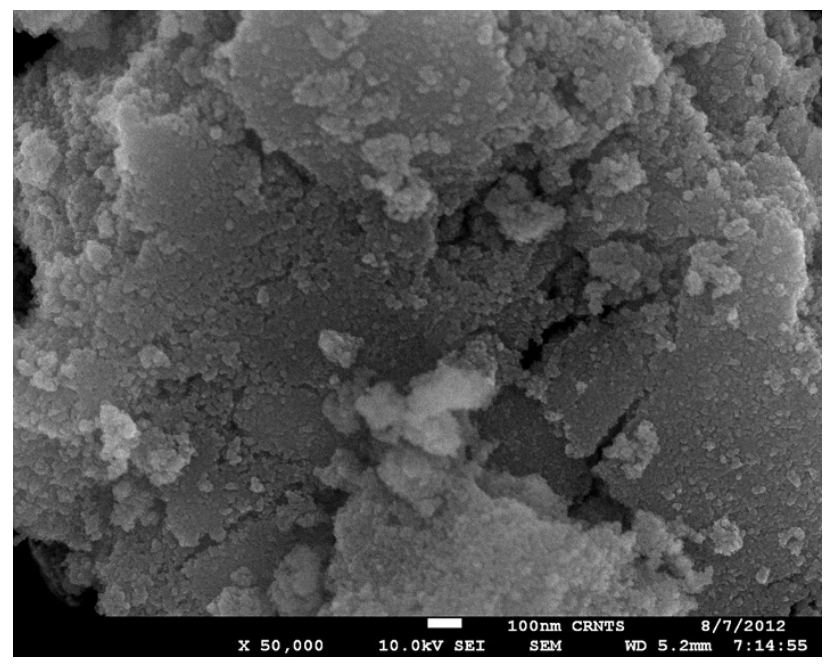

Fig. 5 SEM image of $\mathrm{CS}-\mathrm{ZnFe}_{2} \mathrm{O}_{4}$

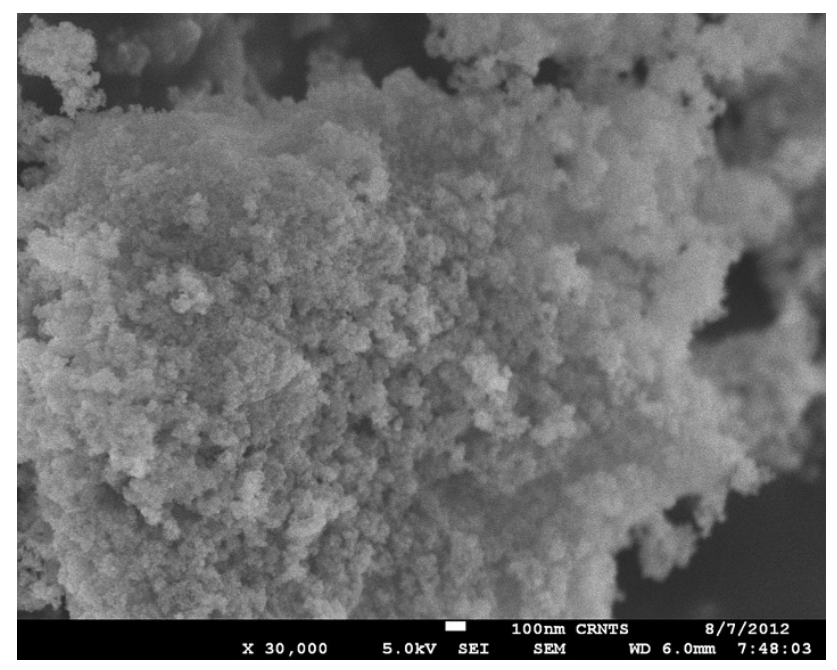

Fig. 6 SEM image of $\mathrm{MS}-\mathrm{ZnFe}_{2} \mathrm{O}_{4}$

particle sizes obtained from XRD (Debye-Scherrer formula) and TEM are tabulated in Table 1.

The functional groups identification of CS and MS$\mathrm{ZnFe}_{2} \mathrm{O}_{4}$ are investigated by FT-IR spectra of powder, at room temperature, as shown in Fig. 9a, b. The FTIR spectra of both the samples exhibit peak at 675.40 and $527.27 \mathrm{~cm}^{-1}$ that can be assigned to stretching vibration modes associated with the $\mathrm{Fe}-\mathrm{O}$ and $\mathrm{Zn}-\mathrm{O}$ absorption bands, respectively, in the crystalline lattice of $\mathrm{ZnFe}_{2} \mathrm{O}_{4}$.

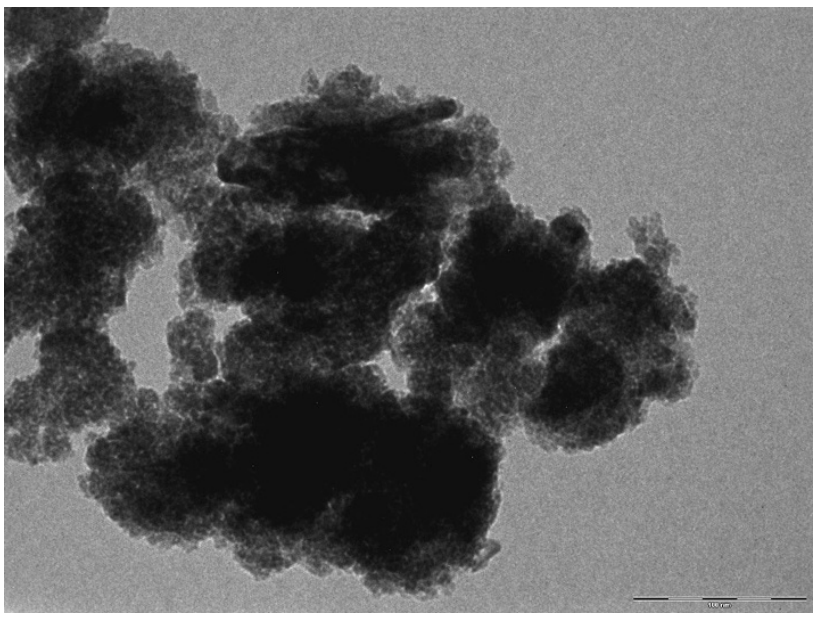

Fig. 7 TEM image of CS- $\mathrm{ZnFe}_{2} \mathrm{O}_{4}$

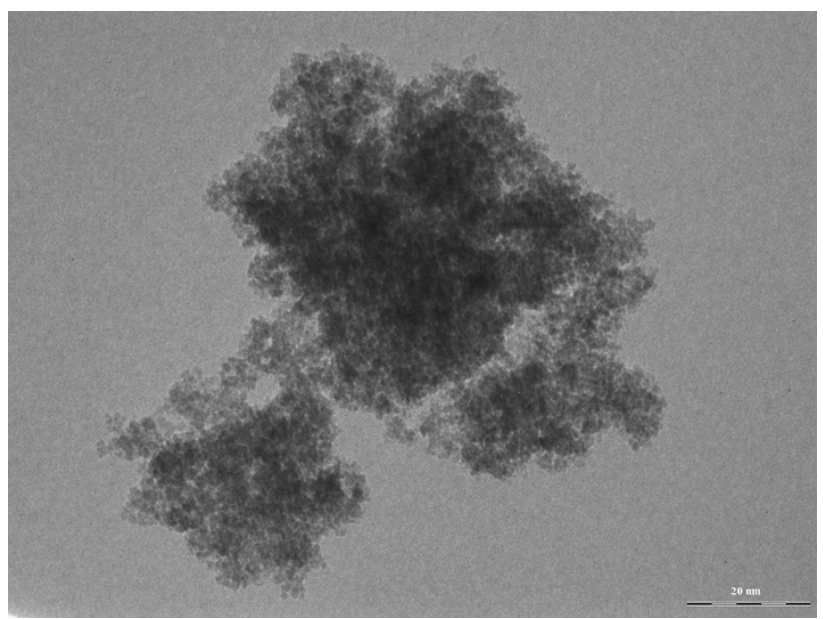

Fig. 8 TEM image of MS- $\mathrm{ZnFe}_{2} \mathrm{O}_{4}$

They are characteristically pronounced for all spinel structures and for ferrite particularly. This occurs because the stretching vibration bands related to metal in the octahedral and the tetrahedral sites are in this region. FTIR spectra also show an absorption band at 2,363.18, 1,741.31, $1,368.33$, and $1,214.54 \mathrm{~cm}^{-1}$ in both the samples, which are found to be associated with the stretching vibrations of $\mathrm{C}-\mathrm{H}, \mathrm{C}=\mathrm{O}, \mathrm{C}-\mathrm{O}$, and $\mathrm{H}-\mathrm{C}-\mathrm{H}$, respectively.

Raman spectra of the $800{ }^{\circ} \mathrm{C}$-calcined $\mathrm{CS}$ and MS$\mathrm{ZnFe}_{2} \mathrm{O}_{4}$ nanoparticles are shown in Fig. 10 . The $800{ }^{\circ} \mathrm{C}$ - 


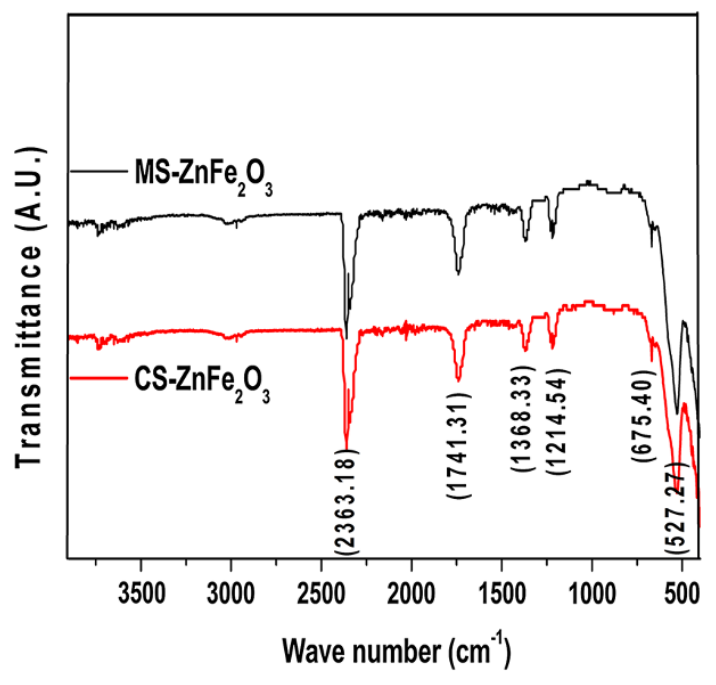

Fig. 9 Comparative FTIR spectra of CS and MS- $\mathrm{ZnFe}_{2} \mathrm{O}_{4}$

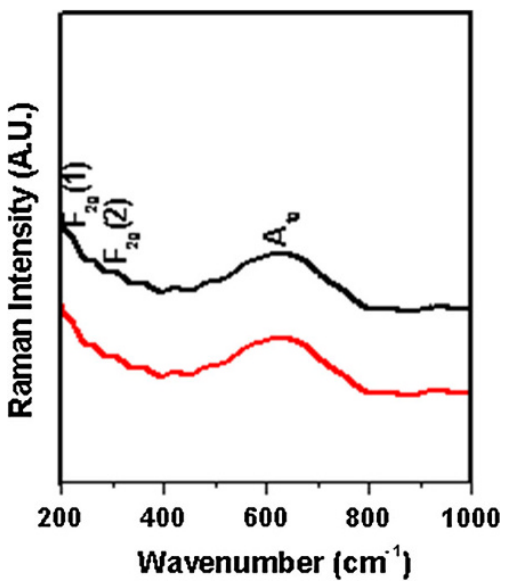

Fig. 10 Comparative Raman spectra of CS and $\mathrm{MS}-\mathrm{ZnFe}_{2} \mathrm{O}_{4}$

calcined sample exhibits the spinel phase. The average crystallite sizes are $4-5 \mathrm{~nm}$ for both samples. The space group of the cubic spinel zinc ferrite is $\mathrm{O}_{\mathrm{h}}^{7}\left(\mathrm{Fd}_{3 \mathrm{~m}}\right)$ with eight formula units per unit cell. According to group theory, zinc has the following sets of optical phonon modes at the $\Gamma$ point of the Brillouin zone:

$$
\begin{aligned}
\mathrm{T}= & \mathrm{A}_{1 \mathrm{~g}}(\mathrm{R})+\mathrm{E}_{\mathrm{g}}(\mathrm{R})+\mathrm{F}_{1 \mathrm{~g}}+3 \mathrm{~F}_{2 \mathrm{~g}}(\mathrm{R})+2 \mathrm{~A}_{2 \mathrm{u}} \\
& +2 \mathrm{E}_{\mathrm{u}}+4 \mathrm{~T}_{14}(\mathrm{IR})+2 \mathrm{~F}_{2 \mathrm{u}}
\end{aligned}
$$

There are five first-order Raman active modes $\left(\mathrm{A}_{1 \mathrm{~g}}+\mathrm{E}_{\mathrm{g}}+3 \mathrm{~F}_{2 \mathrm{~g}}\right)$ and all these modes were observed at ambient conditions. In the present work, the visual inspection of the spectrum shows that both the samples have three Raman bands 217,326 , and $630 \mathrm{~cm}^{-1}$ in the range $200-1,100 \mathrm{~cm}^{-1}$. The observed modes were assigned according to Wang et al. in which the author had studied the high-pressure behavior of zinc ferrites [40]. The identified phonon modes of the sample are marked on the
Raman spectrum; the bands at $217 \mathrm{~cm}^{-1}$ to $F_{2 \mathrm{~g}}(1)$, the band at $326 \mathrm{~cm}^{-1}$ to $\mathrm{F}_{2 \mathrm{~g}}(2)$, and the band at $630 \mathrm{~cm}^{-1}$ to $\mathrm{A}_{1 \mathrm{~g}}$ modes of both the samples at room temperature. The crystallite size leads to broadening of the Raman modes. Comparative structural study of CS and $\mathrm{MS}-\mathrm{ZnFe}_{2} \mathrm{O}_{4}$ clearly shows that the microwave heating route develops the same quality of Zinc ferrites as conventional ones; in addition, that particles size distribution is more uniform in MS- $\mathrm{ZnFe}_{2} \mathrm{O}_{4}$ compared to CS.

\section{Conclusion}

Nanoparticles of Zinc ferrites are prepared by the coprecipitation route and the role of mode of heating on structure and microstructure are systematically studied. The structure of the formation was confirmed by XRD. XRD data ensured the presence of single-phase face-centered cubic structure for both the samples. The XRD data are well fitted with Reitveld refinement. The microstructure of the samples were studied by SEM and TEM images and found to be in the range of 4-5 $\mathrm{nm}$. Microwave-processed MS$\mathrm{ZnFe}_{2} \mathrm{O}_{4}$ was found to have highly uniform particle size distribution with less agglomeration as compared to conventionally processed sample $\left(\mathrm{CS}-\mathrm{ZnFe}_{2} \mathrm{O}_{4}\right)$. The functional groups were analyzed by FT-IR. Local distortion due to very small crystallite distribution in the structures was studied by FT-Raman spectra of zinc ferrites at room temperature. The microwave-assisted route was found to be faster route of synthesis and highly controlled method for nanostructured ferrites-based materials.

Acknowledgments The authors are thankful to IISER, Pune, Bhopal, and IIT Mumbai for providing facility for XRD, TEM, and Raman study of the materials.

Open Access This article is distributed under the terms of the Creative Commons Attribution License which permits any use, distribution, and reproduction in any medium, provided the original author(s) and the source are credited.

\section{References}

Atif M, Hasanain SK, Nadeem M (2006) Solid State Commun 138:416

Bettinger JS, Chopdekar RV, Liberati M, Neulinger JR, Zhshiev, Akamwa Y (2007) J Magn Magn Mater 318:65

Bid S, Pradhan SK (2003) Mater Chem Phys 82:27

Changwa Y, Qiaoshi Z, Goya GF, Torres T, Jinfang L, Haiping W, Mingyuan G, Yuewu Z, Youwen W, Jiang JZ (2007) J Phys Chem C 111:12274

Deng H, Li X, Peng Q, Wang X, Chen J, Li Y (2005) Angew Chem Int Ed 44:2782

Ehrhardt H, Campbell SJ, Hofmann M (2003) Scripta Mater 48:1141

El-Sayed MA (2004) Acc Chem Res 37:326 
Geng BY, Ma JZ, Liu XW, Du QB, Kong MG, Zhang LD (2007) Appl Phys Lett 90:043120

Grasset F, Labhsetwar N, Li D et al (2002) Langmuir 18:8209

Gul IH, Ahmed W, Maqsood A, Ortiz-Vitoriano N, Bernuy-López C, Ruiz de Larramendi I, Knibbe R, Thydén K, Hauch A, Holtappels P, Rojo T (2013) Appl Energy 104:984-991

Huayun Xu, Chen Xianglan, Chen Liang, Li Li'e, Xu Liqiang, Yang Jian, Qian Yitai (2012) Int J Electrochem Sci 7:7976

Ikenaga N-O, Ohgaito Y, Matsushima H, Suzuki T (2004) Fuel 83:661

Jeyadevan B, Tohji K, Nakatsuka K (1994) J Appl Phys 76:6325

Kobayashi M, Shirai H, Nunokawa M (2002a) Ind Eng Chem Res 41:2903

Kobayashi M, Shirai H, Nunokawa M (2002b) Energy Fuels 16:1378

Kumar P (1999) Handbook of microemulsion science and technology, 1st edn. Marcel Dekker, New York

Kumar A, Varshney D (2012) Ceram Int 38:3935-3942

Kundu A, Upadhyay C, Verma HC (2003) Phys Lett A 311:410

Li FS, Wang HB, Wang L, Wang JB (2006) J Magn Magn Mater 309:295

Lu AH, Salabas EL, SchÜth F (2007) Angew. Chem. 46:1222

Niu X, Du W, Du W (2004) Sensors Actuators B 99:405

Oliver SA, Harris VG, Hamdeh HH, Ho JC (2000) Appl Phys Lett 76:2761

Ozcan S, Kaynar B, Can MM, Firat T (2005) Mater Sci Eng B 121:278

Pineda M, Palacios JM, Garćı E, Cilleruelo C, Ibarra JV (1997) Fuel 76:567
Qiu J, Wang C, Gu M (2004) Mater Sci Eng B 112:1

Roduner E (2006) Chem Soc Rev 35:583

Sepelak V, Zatroch M, Tkacova K, Petrovic P, Wibmann S, Becker KD (1997) Mater Sci Eng A 22:226

Sivakumar M, Towata A, Yasui K, Tuziuti T, Iida Y (2006) Curr Appl Phys 6:591

Son S, Taheri M, Carpenter E, Harris VG, McHenry ME (2002) J Appl Phys 91:7589

Sousa MH, Tourinho FA, Depeyrot J, Da Silva GJ, Lara MCFL (2001) J Phys Chem B 105:1168

Tanaka K, Makita M, Shimizugawa Y, Hirao K, Soga N (1998) J Phys Chem Solids 59:1611

Toledo-Antonio JA, Nava N, Martınez M, Bokhimi X (2002) Appl Catal A 234:137

Toḿas-Alonso F, Latasa JMP (2004) Fuel Process Technol 86:191

Tung LD, Kolesnichenko V, Caruntu G, Caruntu D, Remond Y, Golub VO, O'Connor CJ, Spinu L (2002) Phys B 319:116

Wakiya N, Muraoka K, Kiguchi T, Mizutani N, Shinozaki K (2007) J Magn Magn Mater 310:2546

Wang ZW, Lazor P, Saxena SK, Aritoli G (2002) J Solid State Chem 165:165

Yadoji P, Peelamedu R, Agrawal D, Roy R (2003) Mater Sci Eng B 98:269

Yin Y, Alivisatos AP (2005) Nature (London) 437:664 